\title{
Inhibition of CD9 expression reduces the metastatic capacity of human hepatocellular carcinoma cell line MHCC97-H
}

\author{
QING LIN ${ }^{1}$, SHIFANG PENG ${ }^{2,3}$ and YIXUAN YANG ${ }^{1,4,5}$ \\ ${ }^{1}$ Department of Infectious Diseases, The Second Affiliated Hospital of Chongqing Medical University, Chongqing 400010; \\ Departments of ${ }^{2}$ Infectious Diseases and ${ }^{3}$ Health Management Center, Xiangya Hospital, Central South University, \\ Changsha, Hunan 410008; ${ }^{4}$ Institute for Viral Hepatitis of Chongqing Medical University; \\ ${ }^{5}$ Key Laboratory of Molecular Biology for Infectious Diseases, Ministry of Education, \\ Chongqing Medical University, Chongqing 400016, P.R. China
}

Received November 12, 2017; Accepted April 17, 2018

DOI: $10.3892 /$ ijo.2018.4381

\begin{abstract}
Metastasis is a characteristic of malignant tumors and may be a fatal clinical factor for many patients with cancer. Hepatocellular carcinoma (HCC) cells are highly metastatic; the mechanism of metastasis is complicated and may be influenced by a number of factors. Membrane proteins may block receptors or inhibit important enzymes, thus inhibiting tumor progression, and may be potential therapeutic targets for tumor prognosis and treatment. The present study aimed to use proteomics to analyze the dynamic changes of membrane proteins in HCC cells, to improve our understanding of membrane protein functions and to clarify the important components of the mechanisms of HCC metastasis. The present study used the highly metastatic MHCC97-H and the lowly metastatic MHCC97-L HCC cell lines, and the isobaric tags for relative and absolute quantitation (iTRAQ) approach was used for high-throughput screening of metastasis-related membrane proteins. A total of 22 membrane proteins were identified as differentially expressed between the MHCC97-H and MHCC97-L cell lines; these results were verified by reverse transcription-quantitative polymerase chain reaction and western blotting. A number of the identified proteins were revealed to be related to tumor metastasis, including the tetraspan in transmembrane protein CD9. CD9 was demonstrated to be highly expressed in MHCC97-H cells compared with MHCC97-L cells. The functional role of CD9
\end{abstract}

Correspondence to: Professor Yixuan Yang, Department of Infectious Diseases, The Second Affiliated Hospital of Chongqing Medical University, 76 Linjiang Road, Chongqing 400010, P.R. China E-mail: yxyangooo@sohu.com

Professor Shifang Peng, Department of Infectious Diseases, Xiangya Hospital, Central South University, 87 Xiangya Road, Changsha, Hunan 410008, P.R. China

E-mail: sfp1988@csu.edu.cn

Key words: hepatocellular carcinoma, CD9, isotope tags for relative and absolute quantitation was characterized by inhibiting its expression using a small interfering RNAs, which demonstrated that reduced CD9 expression inhibited cell migration and metastasis, as determined by wound-healing and invasion assays. Results from the present study demonstrated that CD9 was highly expressed in the highly metastatic HCC cells and promoted HCC cell migration. This protein may be a novel target for regulating the invasive phenotype in HCC.

\section{Introduction}

Hepatocellular carcinoma (HCC) is one of the most common malignancies and is the second leading cause of cancer-related mortalities worldwide (1-3). HCC prognosis remains poor because tumors are frequently diagnosed at a late stage that may not treatable by surgical resection (4). Owing to the high rates of metastasis and recurrence following curative resection, understanding the underlying mechanisms of tumor metastasis is crucial for the development of effective therapeutic targets against HCC that may be used as new targets for treatment and as potential diagnostic markers (5). Membrane proteins are abundant biomolecules, a number of which have been used as tumor markers or drug targets; approximately one-third of protein tumor markers are membrane proteins (6). Membrane proteins serve an important role in cell survival, growth, division and differentiation $(7,8)$. Signal transduction, material transport, adhesion and immunogenicity of cells may be altered by membrane proteins, such as receptor proteins, transporter proteins, adhesion protein expression and antigens $(6,9)$. It has been reported previously that membrane proteins are closely related to malignant tumor cell invasion and metastasis, such as epithelial membrane protein 1 and lysosome-associated membrane protein1 (10-12). Therefore, the present study used a proteomics method to identify differentially expressed membrane proteins in two metastatic HCC cell lines. The profiling of differentially expressed proteins in different tumoral states is essential to understanding the mechanisms of tumor progression, and may aid future studies in identifying new therapeutic targets.

Advancements in proteomics have permitted the quantitative detection and accurate monitoring of changes in protein 
expression levels (13). Isobaric tags for relative and absolute quantitation (iTRAQ) technology is a powerful tool and is used for its selectivity, sensitivity and specificity to identify proteins that are differentially expressed in tumors (14). In the present study, iTRAQ was used to identify differentially expressed membrane proteins between two human HCC cell lines with differing metastatic potentials. The lowly metastatic MHCC97-L and the highly metastatic MHCC97-H cell lines were established from the metastatic hepatocellular carcinoma cell line MHCC97 by Li et al (15). These two cell lines have been widely used to investigate the mechanisms of human HCC metastasis, to identify the membrane proteins that may be associated with HCC cell metastasis and to provide clues for early diagnosis and treatment (16-19).

\section{Materials and methods}

Cell lines and culture conditions. The human HCC cell lines MHCC97-Hand MHCC97-L were purchased from the Liver Cancer Institute of Fudan University (Shanghai, China). Cells were cultured in complete Dulbecco's modified Eagle's medium (DMEM; HyClone; GE Healthcare Life Sciences, Logan, UT, USA) containing 10\% fetal bovine serum (FBS; Gibco; Thermo Fisher Scientific, Inc., Waltham, MA, USA) and $100 \mathrm{U} / \mathrm{ml}$ penicillin (Invitrogen; Thermo Fisher Scientific, Inc.), and incubated at $37^{\circ} \mathrm{C}$ in a humidified atmosphere containing $5 \%$ carbon dioxide.

Cell membrane protein collection. Membrane proteins were extracted using a CelLytic MEM Protein Extraction kit (Sigma-Aldrich; Merck KGaA, Darmstadt, Germany), following the manufacturer's protocol. A total between $1 \times 10^{6}$ and $1 \times 10^{7}$ cells were collected and resuspended in $600 \mu \mathrm{l}$ ice-cold Lysis and Separation Working Solution, provided in the kit, containing $6 \mu \mathrm{l}$ protease inhibitor cocktail. Cell suspensions were incubated on ice for $10 \mathrm{~min}$ and subsequently centrifuged in a pre-cooled $\left(4^{\circ} \mathrm{C}\right)$ microcentrifuge at $10,000 \mathrm{x}$ g for $5 \mathrm{~min}$. The clarified lysates were transferred to a sterile microcentrifuge tube, incubated at $30^{\circ} \mathrm{C}$ for $3-5 \mathrm{~min}$ and centrifuged at room temperature $\left(>20^{\circ} \mathrm{C}\right)$ at $3,000 \mathrm{x}$ g for $3 \mathrm{~min}$. The lower, hydrophobic phase, which is enriched with hydrophobic and lipid raft-associated proteins, was transferred to a new microcentrifuge tube and stored at $-20^{\circ} \mathrm{C}$ until use.

iTRAQ labeling. The 8-plex iTRAQ kits were obtained from Applied Biosystems (Thermo Fisher Scientific, Inc.), and experiments were conducted according to the manufacturer's protocol. Briefly, protein concentrations were quantified by Bicinchoninic Acid assay (BCA; Qcbio Science \& Technologies Co., Ltd., Shanghai, China) and $\sim 100 \mu \mathrm{g}$ of prepared proteins from each group were precipitated, dissolved in dissolution buffer, denatured, cysteine blocked, digested with $2 \mu \mathrm{g}$ of sequencing grade modified trypsin, and labeled with the iTRAQ tags; MHCC97-L proteins were labeled with the iTRAQ-113 tag and MHCC97-H proteins were labeled with the iTRAQ-115 tags. A schematic view of the iTRAQ methodology is shown in Fig. 1; the experiments were repeated twice.

Peptide fractionation. iTRAQ-labeled peptides were fractionated by immobilized $\mathrm{pH}$ gradient-isoelectric focusing (IPG-IEF).
Briefly, the pooled iTRAQ-labeled peptide samples were solubilized in $300 \mu \mathrm{l}$ of $8 \mathrm{M}$ urea and $1 \%$ Pharmalyte solution, and rehydrated on an $18 \mathrm{~cm}-$ long IPG gel strips ( $\mathrm{pH} 3-10)$ (both from Amersham; GE Healthcare Life Sciences, Little Chalfont, UK) for $14 \mathrm{~h}$ at $30 \mathrm{~V}$. The peptides were subjected to IEF at $68 \mathrm{kV} / \mathrm{h}$ with an IPGphor IEF System (Amersham; GE Healthcare Life Sciences). Peptides were extracted by incubating the gel fractions in $2 \%$ acetonitrile and $0.1 \%$ formic acid for $1 \mathrm{~h}$ at room temperature. Fractions were purified and concentrated on a C-18 Discovery DSC-18 SPE column (Sigma-Aldrich; Merck KGaA). The desalted fractions were lyophilized and stored at $-20^{\circ} \mathrm{C}$ until used in liquid chromatograph-tandem mass spectrometry (LC-MS/MS) analysis.

LC-MS/MS and bioinformatics. Mass spectrometric analysis was performed on a QStar Elite mass spectrometer (Applied Biosystems; Thermo Fisher Scientific, Inc.) coupled to an online capillary LC Dionex Ultimate 3000 system (Thermo Fisher Scientific, Inc.), as previously described $(20,21)$. The peptide separation was performed on a PepMap C-18RP capillary column (Thermo Fisher Scientific, Inc.) with a flow rate of $0.3 \mu \mathrm{l} / \mathrm{min}$ using a linear gradient ranging between 2 and $100 \%$ Buffer B (0.1\% formic acid; $98 \%$ acetonitrile) for $90 \mathrm{~min}, 2.1 \mathrm{kV}$, and flow rate of $300 \mathrm{nl} / \mathrm{min}$. Data acquisition was performed in the positive ionization mode with a selected mass range of $300-1,800 \mathrm{~m} / \mathrm{z}$. The two most intensely charged peptides with $>20$ counts were chosen for MS/MS with a dynamic exclusion of $30 \mathrm{sec}(22)$.

Protein identification and quantification were performed using ProteinPilot software v2.0 (Applied Biosystems/MDS Sciex Joint Venture; Thermo Fisher Scientific, Inc.; Nordion, Inc., Ottawa, ON, Canada). MS/MS data were analyzed with the UniProt database (http://www.uniprot.org). Differentially expressed proteins were indicated as having a protein score $>1.3(1.3 / 1)$ or $<0.77(1 / 1.3)$ (Table I), and $>2$ unique peptides with $95 \%$ confidence and $\mathrm{P}<0.05$ were required for quantitation.

Reverse transcription-quantitative polymerase chain reaction $(R T-q P C R)$ analysis. Total RNA was isolated from $1 \times 10^{5}-1 \times 10^{7}$ cells using TRIzol (Invitrogen; Thermo Fisher Scientific, Inc.), according to the manufacturer's instructions. First strand cDNA was synthesized using $2 \mu \mathrm{g}$ total RNA and the A3500 Reverse Transcription System (Promega, Madison, WI, USA). The resulting cDNA was amplified by PCR using an ABI 7300 system (Applied Biosystems; Thermo Fisher Scientific, Inc.), SYBR Premix Ex Taq II (Tli RNaseH Plus) and ROX plus reference dye (Takara Bio, Inc., Otsu, Japan). Gene-specific primer sequences are provided in Table II. PCR thermocycling conditions were as follows: $95^{\circ} \mathrm{C}$ for $15 \mathrm{sec}$ followed by 35 cycles of $72^{\circ} \mathrm{C}$ for $30 \mathrm{sec}$ and $60^{\circ} \mathrm{C}$ for $60 \mathrm{sec}$. PCR reactions were evaluated by melting curve analysis, and relative gene expression levels were calculated according to the $2^{-\Delta \Delta \mathrm{Cq}}$ method and normalized to the internal reference gene GAPDH (23). Experiments were performed at least three times and similar results were obtained in each experiment.

Western blotting. Cells were lysed and fractionated using a CelLytic MEM Protein Extraction Kit (Sigma-Aldrich; Merck KGaA), as aforementioned. Total protein was quantified by $\mathrm{BCA}$, and equal amounts of proteins (30 $\mu \mathrm{g}$ protein/lane) 
Table I. List of differentially expressed proteins between MHCC97-H and MHCC97-L cell lines identified by iTRAQ proteomics analysis.

\begin{tabular}{|c|c|c|c|c|c|c|c|}
\hline $\mathrm{n}$ & Unused & Accession no. & Gene & Protein name & $\begin{array}{l}\text { Peptides } \\
(95 \% \mathrm{CI})\end{array}$ & $\begin{array}{l}\text { iTRAQ ratios } \\
(115: 113)\end{array}$ & $\begin{array}{c}\text { P-value } \\
(115: 113)\end{array}$ \\
\hline \multicolumn{8}{|c|}{ Downregulated proteins } \\
\hline 1 & 6.2 & splP68402|PA1B2_HUMAN & PAFAH1B2 & $\begin{array}{l}\text { Platelet-activating factor } \\
\text { acetylhydrolase IB subunit } \beta\end{array}$ & 3 & 0.5688 & 0.0205 \\
\hline 2 & 13 & splQ9UHL4IDPP2_HUMAN & $\mathrm{DPP} 2$ & Dipeptidyl peptidase 2 & 7 & 0.6872 & 0.0380 \\
\hline 3 & 4.15 & splQ15386|UBE3C_HUMAN & UBE3C & Ubiquitin-protein ligase E3C & 6 & 0.7098 & 0.0189 \\
\hline 4 & 4.76 & splQ9Y263|PLAP_HUMAN & PLAA & Phospholipase A-2-activating protein & 7 & 0.7228 & 0.0083 \\
\hline 5 & 23.38 & trlQ53FG31Q53FG3_HUMAN & IFL2 & $\begin{array}{l}\text { Interleukin enhancer binding } \\
\text { factor } 2 \text { variant }\end{array}$ & 20 & 0.7278 & 0.0004 \\
\hline 6 & 6.97 & splQ9NV70|EXOC1_HUMAN & EXOC1 & Exocyst complex component 1 & 4 & 0.7508 & 0.0435 \\
\hline \multicolumn{8}{|c|}{ Upregulated proteins } \\
\hline 1 & 37.28 & splQ9ULC5IACSL5_HUMAN & ACSL5 & Long-chain-fatty-acid-CoA ligase 5 & 20 & 13.068 & 0.0001 \\
\hline 2 & 54.86 & splP05556|ITB1_HUMAN & ITGB1 & Integrin $\beta-1$ & 40 & 13.416 & 10.282 \\
\hline 3 & 20.07 & splP63092|GNAS2_HUMAN & GNAS & $\begin{array}{l}\text { Guanine nucleotide-binding } \\
\text { protein } \mathrm{G}(\mathrm{s}) \text { subunit } \alpha \text { isoforms short }\end{array}$ & 14 & 13.416 & 0.0003 \\
\hline 4 & 9.2 & tr|J3KNF8IJ3KNF8_HUMAN & CYB5B & Cytochrome b5 type B & 13 & 13.451 & 0.0358 \\
\hline 5 & 9.48 & 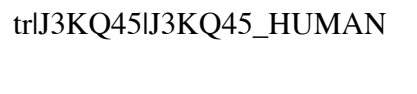 & TGOLN2 & $\begin{array}{l}\text { Trans-Golgi network integral } \\
\text { membrane protein } 2\end{array}$ & 5 & 13.479 & 0.0405 \\
\hline 6 & 5.96 & splQ99871lHAUS7_HUMAN & HAUS7 & $\begin{array}{l}\text { HAUS augmin-like complex } \\
\text { subunit } 7\end{array}$ & 5 & 13.568 & 0.0277 \\
\hline 7 & 10.91 & splP16422IEPCAM_HUMAN & EPCAM & Epithelial cell adhesion molecule & 13 & 13.820 & 0.0021 \\
\hline 8 & 282.04 & splQ09666lAHNK_HUMAN & AHNAK & $\begin{array}{l}\text { Neuroblast differentiation- } \\
\text { associated protein }\end{array}$ & 229 & 13.860 & 85.454 \\
\hline 9 & 12.65 & splQ92542INICA_HUMAN & NCSTN & Nicastrin & 6 & 13.999 & 0.0032 \\
\hline 10 & 45.04 & 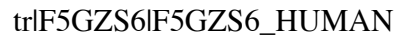 & SLC3A2 & $4 \mathrm{~F} 2$ cell-surface antigen heavy chain & 43 & 14.267 & 38.195 \\
\hline 11 & 6.56 & splQ01650|LAT1_HUMAN & SLC7A5 & $\begin{array}{l}\text { Large neutral amino acids } \\
\text { transporter small subunit } 1\end{array}$ & 7 & 14.293 & 0.0467 \\
\hline 12 & 2.48 & 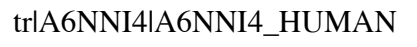 & CD9 & Tetraspanin-29 & 3 & 14.478 & 0.0160 \\
\hline 13 & 10.07 & splQ9H3R2IMUC13_HUMAN & MUC13 & Mucin-13 & 10 & 14.557 & 0.0146 \\
\hline 14 & 42.19 & splQ8IVT2IMISP_HUMAN & MISP & $\begin{array}{l}\text { Mitotic interactor and substrate } \\
\text { of PLK1 }\end{array}$ & 26 & 14.639 & 16.779 \\
\hline 15 & 12.61 & tr|J3KQL8|J3KQL8_HUMAN & APOL2 & Apolipoprotein L2 & 8 & 15.155 & 0.0184 \\
\hline 16 & 4.23 & trlQ53GA9IQ53GA9_HUMAN & CD63 & Tetraspanin-30 & 3 & 17.029 & 0.0457 \\
\hline
\end{tabular}

ACSL5, acyl-CoA synthetase long chain family member 5; AHNAK, AHNAK nucleoprotein; APOL2, apolipoprotein L2; CI, confidence interval; CYB5B cytochrome B5 type B; DPP2, dipeptidyl peptidase 2; EPCAM, epithelial cell adhesion molecule; EXOC1, exocyst complex component 1; GNAS, GNAS complex locus; HAUS7, HAUS augmin-like complex subunit 7; ILF2, interleukin enhancer-binding factor 2; ITGB1, integrin subunit $\beta 1$; iTRAQ, isobaric tags for relative and absolute quantitation; MISP, mitotic spindle positioning; MUC13, mucin 13; NCSTN, nicastrin; PAFAH1B2, platelet activating factor acetylhydrolase 1B catalytic subunit 2; PLAA, phospholipase A2 activating protein; PLK1, polo-like kinase 1; SLC3A2, solute carrier family 3 member 2; TGOLN2, trans-Golgi network protein 2; UBE3C, ubiquitin protein ligase E3C.

were separated by $10 \%$ SDS-PAGE and transferred to a polyvinylidene fluoride membrane (EMD Millipore, Billerica, MA, USA). Membranes were blocked for $1 \mathrm{~h}$ at room temperature in 5\% skim milk powder and TBS $+0.5 \%$ Tween-20 buffer (pH 7.6) and incubated with primary antibodies at $4^{\circ} \mathrm{C}$ overnight. Primary antibodies against PAFAH1B2 (1:1,000; cat. no. ab157479), DPP2 (1:1,000; cat. no. ab226935), UBE3C (1:1,000; cat. no. ab226173), PLAA (1:1,000; cat. no. ab32354), ILF2 (1:1,000; cat. no. ab154169), EXOC1 (1:1,000; cat. no. ab118798), ACSL5 (1:500; cat. no. ab104892), GNAS (1:1,000; cat. no. ab83735), TGOLN2 (1:500; cat. no. ab2809),
HAUS7 (1:500; cat. no. ab192616), EPCAM (1:1,000; cat. no. ab71916), AHNAK (1:1,000; cat. no. ab168104), NCSTN (1:500; cat. no. ab45425), SLC3A2 (1:1,000; cat. no. ab108300), SLC7A5 (1:500; cat. no. ab85226), CD9 (1:1,000; cat. no. ab92726), MUC13 (1:1,000; cat. no. ab124654), MISP (1:200; cat. no. ab175101), APOL2 (1:500; cat. no. ab196771), CD63 (1:1,000; cat. no. ab59479) and ATPase $\mathrm{Na}^{+} / \mathrm{K}^{+}$transporting subunit $\beta 2$ (ATP1B2; 1:1,000; cat. no. ab176163) were purchased from Abcam (Cambridge, MA, USA). ITGB1 (1:1,000; cat. no. 4706) was purchased from Cell Signaling Technology, Inc. (Danvers, MA, USA) and CYB5B (1:250; 


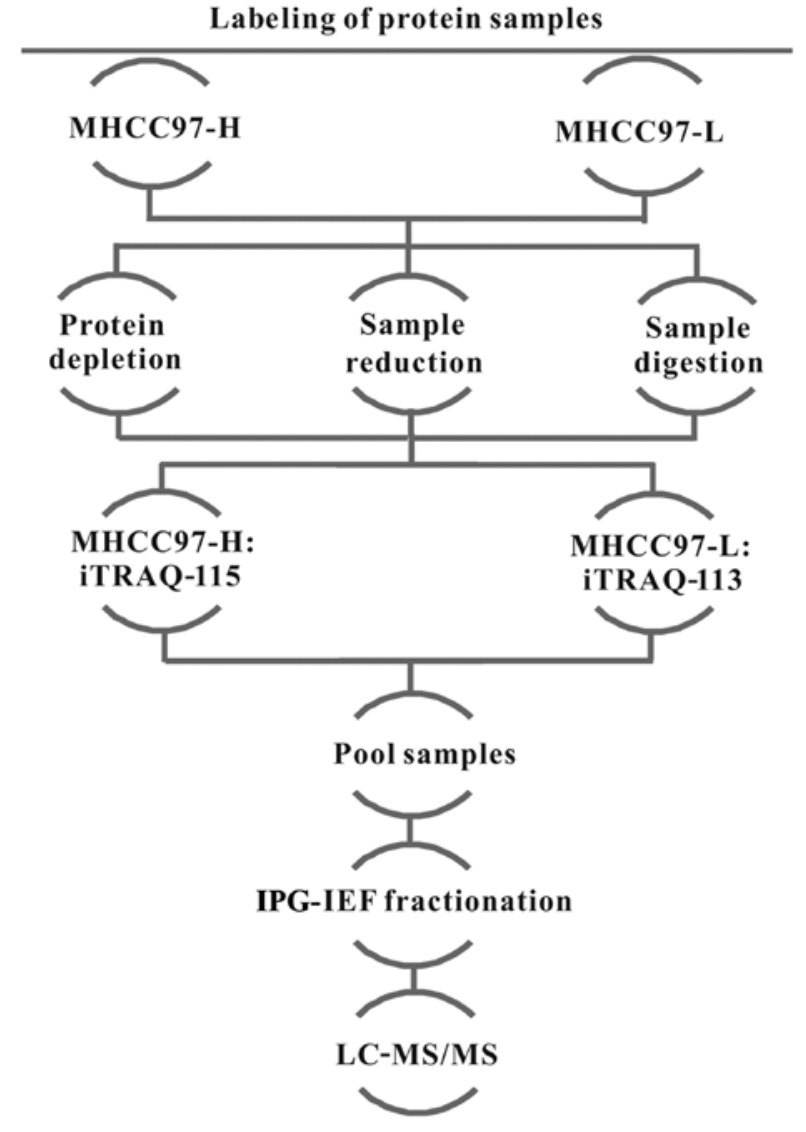

Figure 1. iTRAQ-based MS workflow. IPG-IEF, immobilized pH gradientisoelectric focusing; iTRAQ, isobaric tags for relative and absolute quantitation; LC-MS/MS, liquid chromatograph-tandem mass spectrometry.

cat. no. PA5-52482) was from Invitrogen (Thermo Fisher Scientific, Inc.). Subsequently, membranes were incubated with horseradish peroxidase (HRP)-conjugated goat anti-rabbit $(1: 10,000$; cat. no. ab205718) or goat anti-mouse $(1: 10,000$; cat. no. ab6789) secondary antibodies (Abcam) for $1 \mathrm{~h}$ at room temperature, and protein bands were visualized with the Immobilon Western Chemiluminescent HRP substrate (Merck KGaA) on a ChemiDoc MP imaging system (Bio-Rad Laboratories, Inc., Hercules, CA, USA). Target protein expression levels were analyzed by densitometric analysis with Image Lab v4.0 (Bio-Rad Laboratories, Inc.) and normalized to ATP1B2. Experiments were repeated at least three times.

CD9 small interfering (si)RNA transfection. CD9-targeted siRNA oligomer duplexes siRNA1 (cat. no. 10404) and siRNA2 (cat. no. 145966) and a non-specific, scrambled-siRNA was used as negative control (cat. no. 4390843) were purchased from Invitrogen (Thermo Fisher Scientific, Inc.). MHCC97-H cells $\left(6 \times 10^{5}\right.$ cells/well) were seeded in 6 -well plates $24 \mathrm{~h}$ at $37^{\circ} \mathrm{C}$ prior to transfection. Cells were transfected for $6 \mathrm{~h}$ at $5 \% \mathrm{CO}_{2}$ and $37^{\circ} \mathrm{C}$ with scrambled-siRNA, CD9-siRNA1 or CD9-siRNA2 using Lipofectamine ${ }^{\circledR} 2000$ Transfection Reagent (Invitrogen; Thermo Fisher Scientific, Inc.) and Opti-MEM (Gibco; Thermo Fisher Scientific, Inc.); untreated MHCC97-H cells were used as a blank control. Subsequently, the transfection culture medium was removed and cells were further incubated with complete culture solution for 48 hat $5 \% \mathrm{CO}_{2}$ and $37^{\circ} \mathrm{C}$. Transfected cells were harvested and the
Table II. Gene-specific primer sequences used for polymerase chain reaction.

\begin{tabular}{|c|c|c|}
\hline $\begin{array}{l}\text { Gene } \\
\text { (accession no.) }\end{array}$ & & Primer sequence $\left(5^{\prime} \rightarrow 3^{\prime}\right)$ \\
\hline PAFAH1B2 & $\mathrm{F}:$ & ATCAACACAAGGCAGCCACAGG \\
\hline (NM_002572) & $\mathrm{R}:$ & CAGCGAAACCTTGAGGAGTTGG \\
\hline DPP $\overline{7}$ & & TTCGCCAGCAACAATGTGACCG \\
\hline (NM_013379) & $\mathrm{R}$ : & ATGTTGCTGGCGGCTCTGAGAT \\
\hline UBE3C & F: & GCTCTATGTGCCAGCATCCAGA \\
\hline (NM_014671) & $\mathrm{R}$ : & AGGCAACTCTGTCAGGACAGCA \\
\hline PLAA & F: & AGGCTGGAAGATGTGAGAGGAC \\
\hline (NM_004253) & $\mathrm{R}:$ & TCGCCAGTGATTTGCCACCTTC \\
\hline $\mathrm{ILF}^{-}$ & F: & AGGACTGTTCCTGCCAGGTTCA \\
\hline (NM_004515) & $\mathrm{R}$ : & GAGGATTCGGACGAGAGTCTGA \\
\hline EXOC1 & & CCTATGTCTGGCAGAACAGGAC \\
\hline (NM_018261) & $\mathrm{R}:$ & GCCGTGATAATGTTCCTCCATCC \\
\hline ACSL 5 & F: & GCTTATGAGCCCACTCCTGATG \\
\hline (NM_016234) & $\mathrm{R}:$ & GGAAGAATCCAACTCTGGCTCC \\
\hline ITGB1 & F: & GGATTCTCCAGAAGGTGGTTTCG \\
\hline (NM_033667) & $\mathrm{R}:$ & TGCCACCAAGTTTCCCATCTCC \\
\hline GNAS & F: & GCAGACAGATGCGCAAAGAAGC \\
\hline (NM_001077490) & $\mathrm{R}:$ & GCTTTTACCAGATTCTCCAGCAC \\
\hline CYB5B & & AGGTGGCAAAGCGCAACTCCTT \\
\hline (NM_030579) & $\mathrm{R}:$ & GTTCCAGCAGAACCTCTTCTCC \\
\hline TGOLN2 & F: & GGAGAGCAGCCACTTCTTTGCA \\
\hline (NM_006464) & $\mathrm{R}$ : & CCAAACGTTGGTAGTCACTGGC \\
\hline HAUS7 & & CCTTGGCTCAAGGATTCCGTGA \\
\hline (NM_207107) & $\mathrm{R}:$ & CAGAGGTGTCAGCAACTGCCAT \\
\hline EPCĀM & & GCCAGTGTACTTCAGTTGGTGC \\
\hline (NM_002354) & $\mathrm{R}$ : & CCСTTCAGGTTTTGCTCTTCTCC \\
\hline AHNAK & & CGTGAAGTCTTCAGCTCCTGCA \\
\hline (NM_001620) & $\mathrm{R}:$ & GAGGTCTCCTTCCACTCCATCT \\
\hline NCSTNN & & GGAGGAACCAACTTCAGCGACA \\
\hline (NM_015331) & $\mathrm{R}:$ & TGCCTGAGGATAGACTGGAACC \\
\hline SLC3A2 & F: & CCAGAAGGATGATGTCGCTCAG \\
\hline (NM_002394) & $\mathrm{R}:$ & GAGTAAGGTCCAGAATGACACGC \\
\hline SLC7̄A5 & & GCCACAGAAAGCCTGAGCTTGA \\
\hline (NM_003486) & $\mathrm{R}$ : & ATGGTGAAGCCGATGCCACACT \\
\hline $\mathrm{CD} 9$ & & TCGCCATTGAAATAGCTGCGGC \\
\hline (NM_001769) & $\mathrm{R}:$ & CGCATAGTGGATGGCTTTCAGC \\
\hline MUC13 & & TGGCTGTAACCAGACTGCGGAT \\
\hline (NM_033049) & & GCATCAGGACACTTGAGACTGG \\
\hline MISP & & CACCTACACTCAAACGTGGCGT \\
\hline (NM_173481) & $\mathrm{R}:$ & CCTCTGAGTTGATACCGTCCGA \\
\hline APOL 2 & & GAAGCCTGGAATGGATTCGTGG \\
\hline (NM_030882) & & CGTGGCGGTTTTTGTCCTTCATG \\
\hline $\mathrm{CD} 6 \overline{3}$ & & CAACCACACTGCTTCGATCCTG \\
\hline (NM_001780) & & GACTCGGTTCTTCGACATGGAAG \\
\hline
\end{tabular}

ACSL5, acyl-CoA synthetase long chain family member 5; AHNAK, AHNAK nucleoprotein; APOL2, apolipoprotein L2; CYB5B, cytochrome B5 type B; DPP2, dipeptidyl peptidase 2; EPCAM, epithelial cell adhesion molecule; EXOC1, exocyst complex component 1; F, forward; GNAS, GNAS complex locus; HAUS7, HAUS augmin-like complex subunit 7; ILF2, interleukin enhancer-binding factor 2; ITGB1, integrin subunit $\beta 1$; MISP, mitotic spindle positioning; MUC13, mucin 13; NCSTN, nicastrin; PAFAH1B2, platelet activating factor acetylhydrolase 1B catalytic subunit 2; PLAA, phospholipase A2 activating protein; R, reverse; SLC3A2, solute carrier family 3 member 2; TGOLN2, trans-Golgi network protein 2; UBE3C, ubiquitin protein ligase $\mathrm{E} 3 \mathrm{C}$; F, forward; R, reverse.

expression levels of CD9 mRNA and protein in each sample were confirmed by RT-qPCR and western blotting, respectively. All experiments were repeated at least three times. 
A

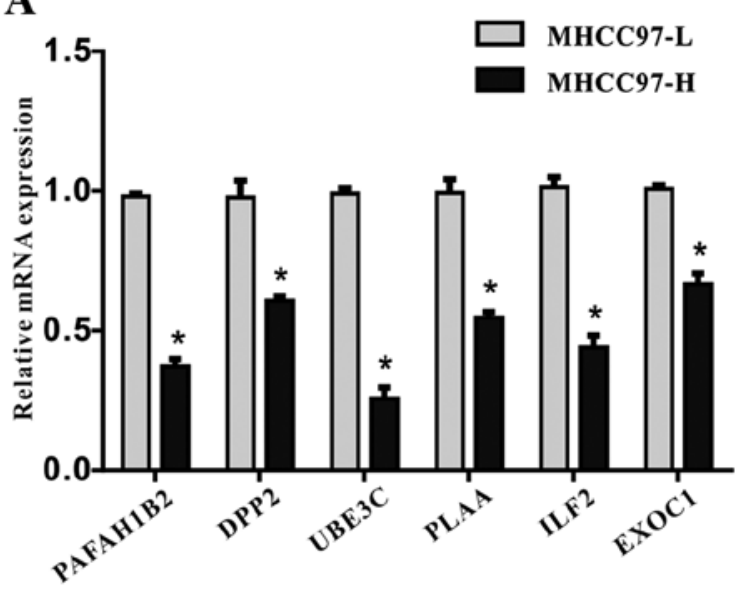

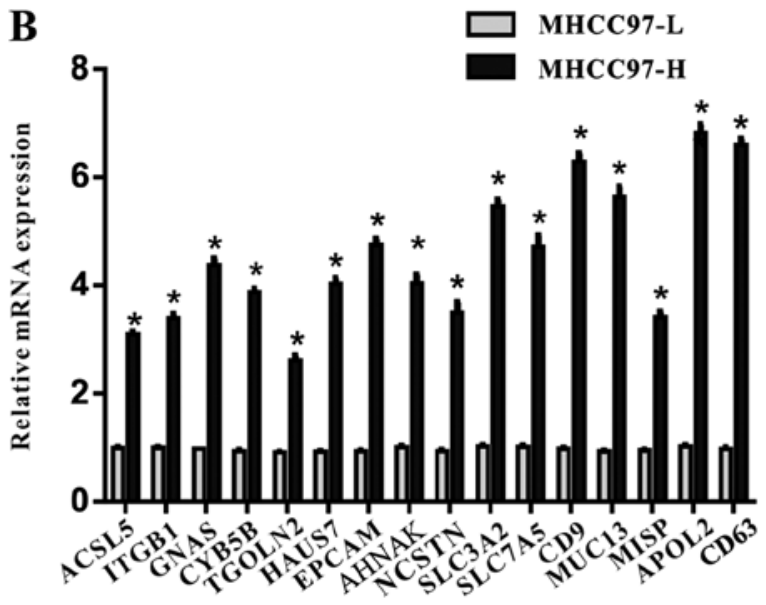
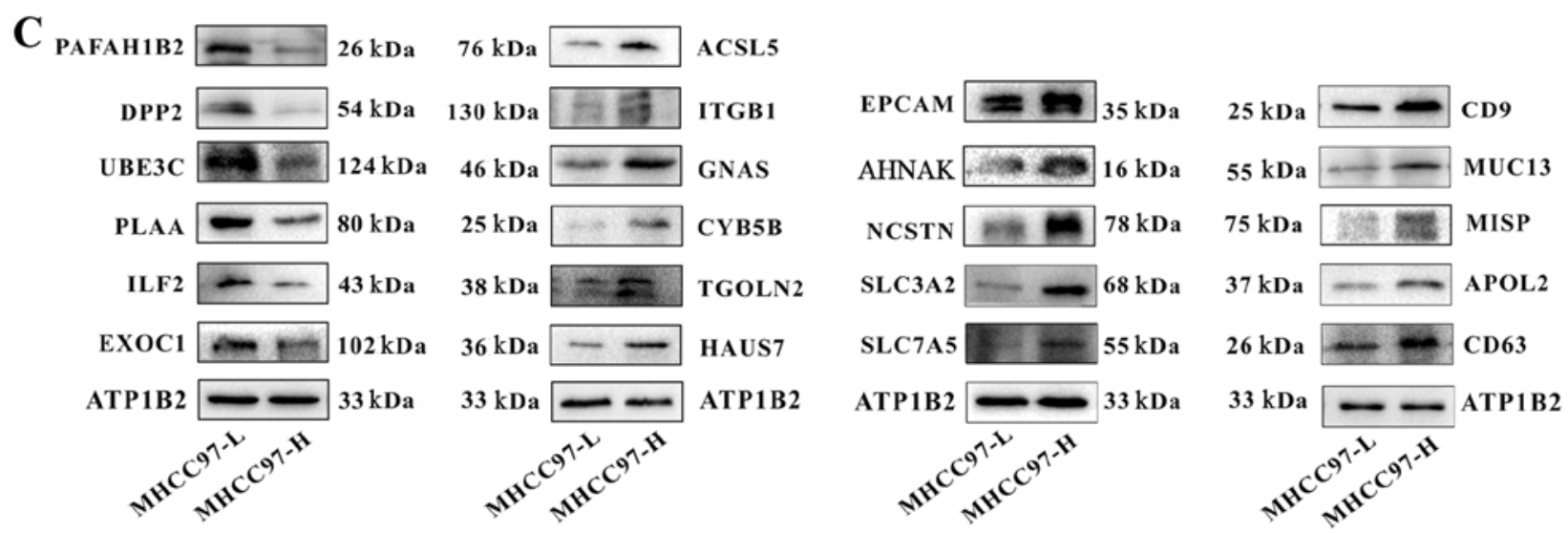

Figure 2. Verification of the differential expression of mRNA and proteins identified by iTRAQ proteomics analysis. (A) RT-qPCR detection of the relative mRNA expression levels of PAFAH1B2, DPP2, UBE3C, PLAA, ILF2 and EXOC1 that were identified by iTRAQ as downregulated in MHCC97-H cells compared with MHCC97-L cells; expression levels were normalized to GADPH. (B) RT-qPCR detection of the relative mRNA expression levels of ACSL5, ITGB1, GNAS, CYB5B, TGOLN2, HAUS7, EPCAM, AHNAK, NCSTN, SLC3A2, SLC7A5, CD9, MUC13, MISP, APOL2 and CD63 that were identified by iTRAQ as upregulated in MHCC97-H cells compared with MHCC97-L cells; expression levels were normalized to GADPH ("P<0.05). (C) Representative western blot analysis of PAFAH1B2, DPP2, UBE3C, PLAA, ILF2, EXOC1, ACSL5, ITGB1, GNAS, CYB5B, TGOLN2, HAUS7, EPCAM, AHNAK, NCSTN, SLC3A2, SLC7A5, CD9, MUC13, MISP, APOL2 and CD63 expression levels in MHCC97-H and MHCC97-L cells; ATP1B2 was used as a loading control. ACSL5, acyl-CoA synthetase long chain family member 5; AHNAK, AHNAK nucleoprotein; APOL2, apolipoprotein L2; ATP1B2, ATPase Na ${ }^{+} \mathrm{K}^{+}$transporting subunit $\beta 2$; CYB5B, cytochrome B5 type B; DPP2, dipeptidyl peptidase 2; EPCAM, epithelial cell adhesion molecule; EXOC1, exocyst complex component 1; GNAS, GNAS complex locus; HAUS7, HAUS augmin-like complex subunit 7 ; ILF2, interleukin enhancer-binding factor 2 ; ITGB1, integrin subunit $\beta 1$; iTRAQ, isobaric tags for relative and absolute quantitation; MISP, mitotic spindle positioning; MUC13, mucin 13; NCSTN, nicastrin; PAFAH1B2, platelet activating factor acetylhydrolase $1 \mathrm{~B}$ catalytic subunit 2; PLAA, phospholipase A2 activating protein; RT-qPCR, reverse transcription-quantitative polymerase chain reaction; SLC3A2, solute carrier family 3 member 2; TGOLN2, trans-Golgi network protein 2; UBE3C, ubiquitin protein ligase E3C.

Wound-healing migration assay. The wound-healing assay was conducted following siRNA transfections to determine the effects on the migratory ability of cells. MHCC97-H cells were seeded in 6-well plates until they reached $100 \%$ confluence at $48 \mathrm{~h}$ post-transfection. A sterile $\mathrm{P} 20$ pipette tip was used to scratch a wound into the cell monolayer and the debris was removed by washing thrice with PBS. The cells were grown in serum-free medium at $37^{\circ} \mathrm{C}$, and digital images of gap closure were captured under a Nikon TS100/TS100-F inverted light microscope (Nikon Corporation, Tokyo, Japan) at 0, 24 and $48 \mathrm{~h}$. Experiments were repeated at least three times.

Invasion assay. Invasion assays were conducted using a Cell Invasion Assay kit (Cell Biolabs, Inc., San Diego, CA, USA). Viable CD9-siRNA1/2 or scrambled-siRNA transfected MHCC97-H cells ( $1 \times 10^{5}$ cells) were harvested and re-suspended in serum-free medium, and used to seed the upper chamber of a 24 -well plate; membranes were precoated with Matrigel. A total of $500 \mu 1 \mathrm{DMEM}+10 \%$ FBS was loaded into the lower chamber. Cells were incubated for $24 \mathrm{~h}$ at $37^{\circ} \mathrm{C}$. Subsequently, cells were washed with PBS and the cells in the upper chamber were wiped off with cotton swab. Cells in the lower chamber were fixed with $4 \%$ formaldehyde at room temperature for $30 \mathrm{~min}$ and stained with $0.1 \%$ crystal violet (Solarbio, Beijing, China) for $20 \mathrm{~min}$ at room temperature. Following three washes with PBS, the number of cells that invaded through the Matrigel was measured by Image-Pro Plus 6.0. At least three fields of views were randomly selected to count cells under an inverted light microscope (magnification, x200). Experiments were repeated at least three times.

Statistical analysis. Statistical analyses were performed using SPSS software v16.0 (SPSS Inc., Chicago, IL, USA). Quantitative variables were presented as the mean \pm standard deviation. Differences between two groups were analyzed by Student's t-test; multiple comparison between the 
A

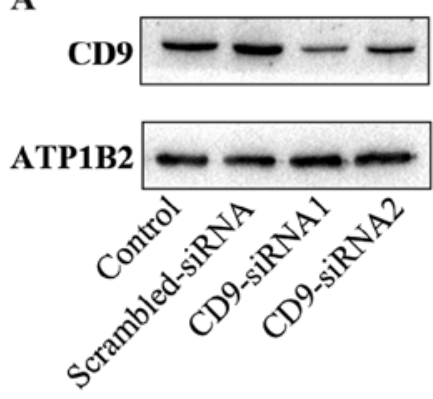

B

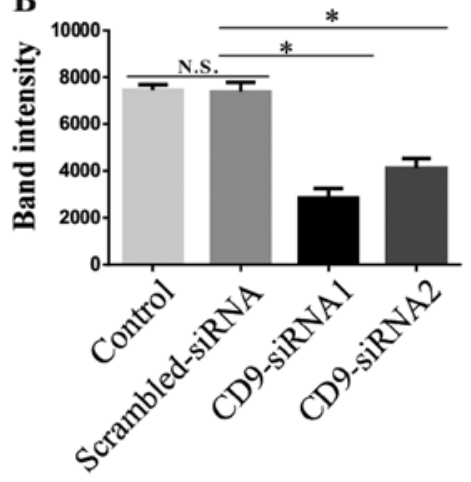

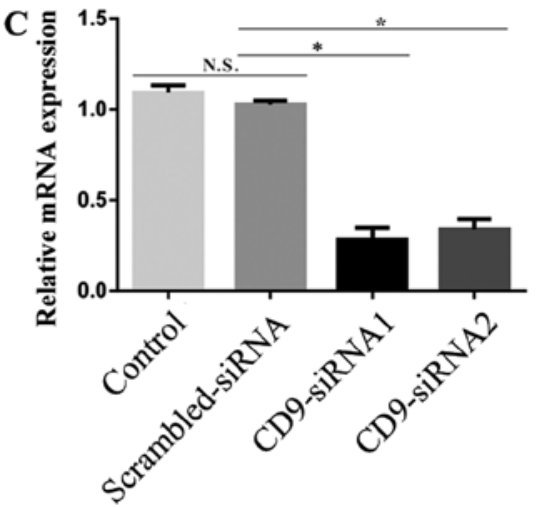

Figure 3. Verification of successful CD9-siRNA transfection. (A) MHCC97-H cells transfected with either CD9-siRNA1 or -siRNA2 exhibited reduced CD9 protein expression; ATP1B2 was used as a loading control (B) Densitometric analysis of CD9 protein expression from (A); ATP1B2 was used as the normalization standard. (C) Similarly, CD9 knockdown significantly reduced mRNA expression levels compared with untransfected control or scrambledsiRNA-transfected negative control cells. Data are presented as the mean \pm standard deviation; ${ }^{*}<0.05 ;$ N.S., not significant; ATP1B2, ATPase Na ${ }^{+} \mathrm{K}^{+}$ transporting subunit $\beta 2$; siRNA, small interfering RNA.

groups were performed by analysis of variance followed by Student-Newman-Keuls post hoc test. $\mathrm{P}<0.05$ was considered to indicate a statistically significant difference.

\section{Results}

iTRAQ comparative proteome analysis. To investigate the mechanisms involved in HCC metastasis, iTRAQ-based MS was conducted to analyze the proteins that were isolated from MHCC97-H and MHCC97-L cell membranes. The ratio of 115-tagged protein expression to 113-tagged protein expressions in MHCC97-H and MHCC97-L samples was used to determine differentially expressed proteins. A total of 780 unique proteins were identified and quantified in each cell line, regardless of whether the P-value was $<0.05$ in the iTRAQ ratios. It has been reported previously that membrane proteins are closely related to malignant tumor cell invasion and metastasis, thus the membrane proteins were classified separately in 780 differentially expressed proteins: 30 membrane proteins as being differentially expressed between MHCC97-L and MHCC97-H cells. Based on the 'Unused' column in Table I (that is, the score of protein confidence level), 20 membrane proteins were verified by RT-qPCR and western blotting, which demonstrated similar mRNA and protein expression levels (Fig. 2). Therefore, 22 proteins were analyzed in this experiment. Of these 22 differentially expressed membrane proteins, 16 were upregulated and 6 were downregulated in the MHCC97-H cell line compared with MHCC97-L cells (Table I).

Validation of differentially expressed proteins. To verify the iTRAQ results, RT-qPCR and western blot analyses were performed. RT-qPCR analysis demonstrated that, compared with expression levels in MHCC97-L cells, the mRNA levels of PAFAH1B2, DPP2, UBE3C, PLAA, IFL2 and EXOC1 were significantly downregulated in MHCC97-H cells (Fig. 2A), whereas ACSL5, ITGB1, GNAS, CYB5B, TGOLN2, HAUS7, EPCAM, AHNAK, NCSTN, SLC3A2, SLC7A5, CD9, MUC13, MISP, APOL2 and CD63 mRNA expression levels were upregulated (Fig. 2B). Western blot analyses were performed to determine the expression levels of these membrane proteins, which revealed a similar pattern of down- and upregulated protein expression levels, as was identified for mRNA in the MHCC97-H cells compared with the MHCC97-L cell (Fig. 2C). The results of mRNA and protein expression were consistent with the iTRAQ results.

CD9 expression is reduced by siRNA treatment. The tetraspanin membrane protein CD9 was demonstrated to be highly expressed in MHCC97-H cells (Fig. 2). CD9 had the lowest score in the 'Unused' column among 22 membrane proteins listed in Table I. The score indicated that CD9 was less accurate compared with other proteins and, therefore, was used to verify the accuracy of iTRAQ. CD9-targeted siRNA1 and siRNA2 were transfected into MHCC97-H cells to silence the expression of CD9. Subsequent western blot analysis demonstrated that CD9 protein expression was reduced in the CD9-siRNAtreated cells compared with the untreated control and scrambled-siRNA-treated groups (Fig. 3A and B). A significant decrease of CD9 mRNA expression levels was also observed intheCD9-siRNA-treated MHCC97-H groups compared with the untreated control and scrambled-siRNA-treated groups (Fig. 3C).

Reduced CD9 expression inhibits $\mathrm{MHCC} 97-\mathrm{H}$ cell migration and invasion. To further examine the role of CD9 in HCC cell motility, wound-healing and invasion assays were performed on untransfected MHCC97-H cells as well as MHCC97-H cells that were transfected with CD9-siRNA1, CD9-siRNA2 or scrambled-siRNA. Results from the wound-healing assay demonstrated that CD9 silencing significantly decreased the migratory ability of MHCC97-H cells transfected with CD9-siRNA1 and CD9-siRNA2 compared with the control groups $(\mathrm{P}<0.05)$ (Fig. 4). Similarly, the CD9-siRNA transfections resulted in significantly decreased invasive ability compared with the control groups $(\mathrm{P}<0.05)$ (Fig. 5).

\section{Discussion}

Membrane proteins may affect the occurrence, development and metastasis of tumors in many ways $(6,9)$. Tumor heterogeneity suggests that the membrane proteins in tumor cells 
A
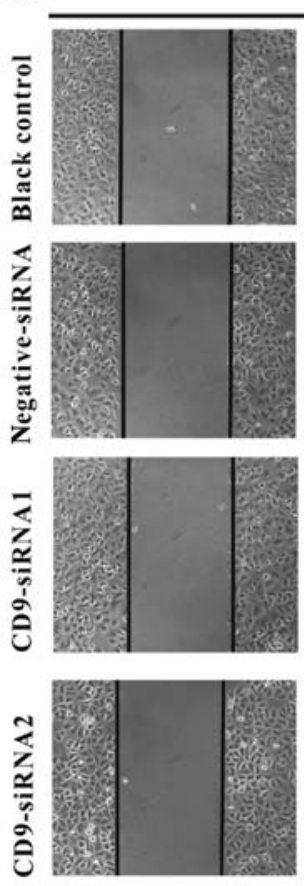

$\mathbf{0 h}$

B

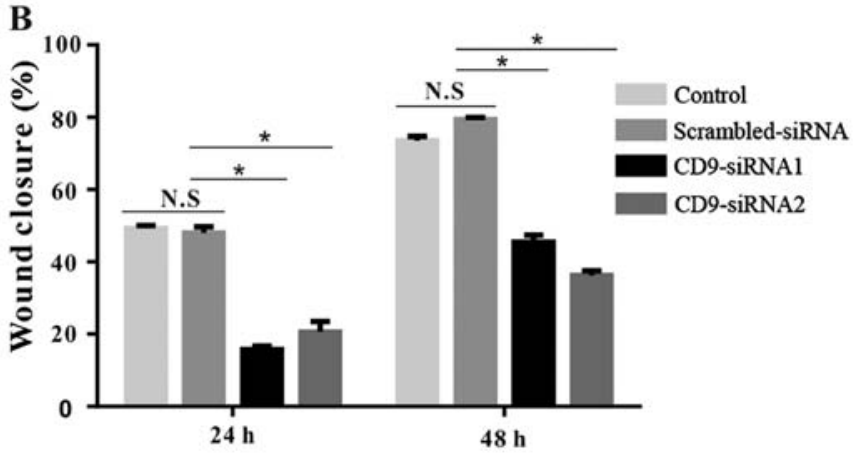

Figure 4. CD9 serves an important role in MHCC97-H cell migration. (A) Wound-healing assays on MHCC97-H cells transfected with CD9-siRNA1, CD9-siRNA2 or scrambled-siRNA negative control, as well as untransfected control cells. Representative images captured at 0,24 and $48 \mathrm{~h}$ are presented. Magnification, x100; Scale bar, $100 \mu \mathrm{m}$. (B) Analysis of wound closure (\%) from (A). Data are presented as the mean \pm standard deviation; "P<0.05; N.S., not significant; siRNA, small interfering RNA.

at differing metastatic potentials may be different $(6,24,25)$. Examination of cytoplasmic membrane proteins in tumor cells may not only reveal the mechanisms of tumor progression, but also may identify reliable tumor markers and drug targets (26-28). Membrane proteins are difficult to dissolve, isolate and identify owing to their heterogeneity, hydrophobicity and low abundance (24), which creates a difficult problem for membrane protein research (25). iTRAQ analysis has become an important tool for protein identification and quantitative analysis. The iTRAQ approach allows for the tagging and detection of peptides, membrane proteins, hydrophobic or macromolecular proteins and proteins that are expressed in low abundance (29). Therefore, the present study used this technique to investigate the membrane proteins in cells with similar genetic backgrounds, but with different metastatic potential, to identify the proteins that may be related to tumor metastasis.
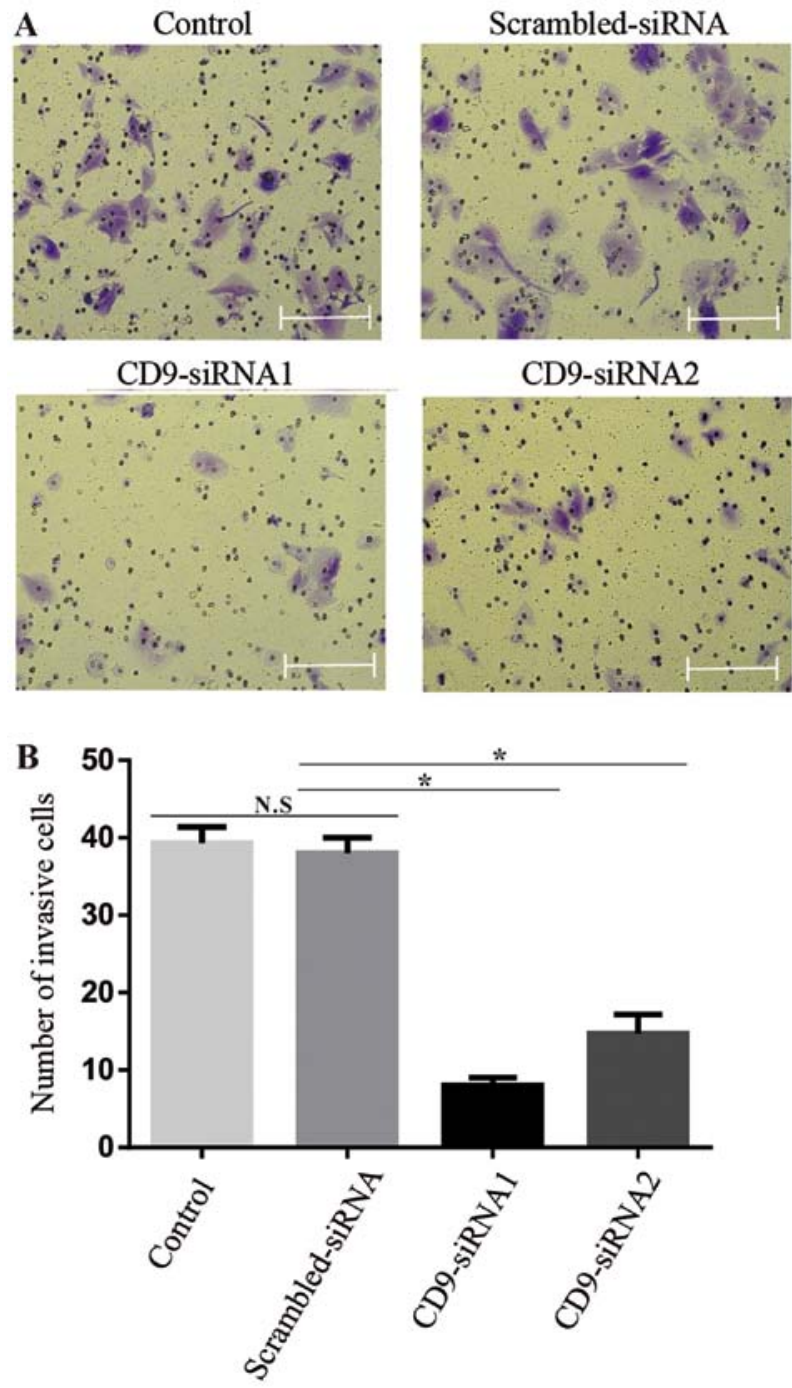

Figure 5. CD9-siRNA transfection reduces the invasive ability of MHCC97-H cells. (A) Invasion assays on MHCC97-H cells transfected with CD9siRNA1, CD9-siRNA2 or scrambled-siRNA, as well as untransfected control cells. Magnification, x200. Scale bar, $100 \mu \mathrm{m}$. (B) The invasive ability was significantly inhibited in CD9-siRNA-transfectedcells compared with the control groups. " $\mathrm{P}<0.05$; N.S., not significant; siRNA, small interfering RNA.

MHCC97-L and MHCC97-H are two subtype cell lines that were established by cloning of the metastatic liver cancer cell line MHCC97 (30). A previous study reported that, although these lines share the same genetic background, the MHCC97-L cell line is characterized by larger cell volume and slower growth, invasion and metastasis, compared with MHCC97-H cells, which exhibit a highly invasive phenotype (31).

In the present study, a total of 16 proteins among the 22 identified as differentially expressed were upregulated in MHCC97-H cells, some of which have been previously reported to serve key roles in tumor metastases, including AHNAK, EPCAM and ITGB1 (32-34). CD9 was one of the highly expressed membrane proteins in MHCC97-H cells.

CD9 is a cell surface glycoprotein that belongs to the tetraspanin superfamily of proteins, which are characterized by the presence of four hydrophobic transmembrane domains (35). Tetraspanin proteins may affect tumorigenesis in a number of ways, such as by promoting or inhibiting tumor growth, 
invasion and metastasis (35-39). CD9 is widely expressed on the cell surface, particularly in malignant tumor cell lines $(37,40)$. Functional studies have demonstrated that CD9 serves a role in tumor cell motility and adhesion, and may have an effect on metastasis (41-43). Previous studies reported that overexpression of CD9 in breast, prostate, colon, lung, neuroblastoma and ovarian carcinoma cells appeared to suppress the motility and metastatic potential of cells (44-49). However, CD9 expression varies greatly among different organ tumors, and may either promote or inhibit metastasis (36). Previous studies have demonstrated that the expression level of CD9 was elevated in certain tumoral cells, such as cervical cancer, prostate cancer and fibrosarcoma, and that CD9 may promote tumor progression (50-52). These data suggested that CD9 may differentially affect particular aspects of tumor growth and progression.

Currently, there are a limited number of studies on the effects of CD9 on the malignant biological behavior of HCC. A previous study suggested that high CD9 expression levels may inhibit liver cancer metastasis (53), and a different study reported that CD9 expression levels were high in healthy liver cells and low in liver parenchymal cells (54). The role of CD9 in liver cancer remains unclear, and the relationship between CD9 expression and HCC metastasis, one of the most metastatic types of tumor, should be further examined in future studies.

In the present study, CD9 was demonstrated to be highly expressed in MHCC97-H cell lines compared with MHCC97-L cells. The functional role of CD9 was characterized using a cell model, which revealed that the migratory capacity was significantly inhibited in MHCC97-H cells following the knockdown of CD9 expression, which was consistent with previous studies that demonstrated a potent role of CD9 in accelerating tumor cell growth (50-52). But the expression of CD9 was reported to be reduced when tumor metastasis occurred in pancreatic cancer and colon cancer $(55,56)$.Future studies will compare normal hepatocytes and HCC cells to further analyze the role of CD9 in the liver. In conclusion, iTRAQ proteomics analysis and cell functional experiments performed in the present study indicated that CD9 may promote metastasis in HCC cells. Results from the wound healing and Matrigel assays suggested that CD9 expression may serve an important role in HCC metastasis and invasion.

\section{Acknowledgements}

Not applicable.

\section{Funding}

No funding was received.

\section{Availability of data and materials}

The datasets used or analyzed during the present study are available from the corresponding author on reasonable request.

\section{Authors' contributions}

YY and SP conceived and designed the study. QL performed the experiments and wrote the paper. YY reviewed and edited the manuscript. All authors read and approved the manuscript.

\section{Ethics approval and consent to participate}

Not applicable.

\section{Consent for publication}

Not applicable.

\section{Competing interests}

The authors declare that they have no competing interests.

\section{References}

1. Chaffer CL and Weinberg RA: A perspective on cancer cell metastasis. Science 331: 1559-1564, 2011.

2. Parkin DM, Bray F, Ferlay J and Pisani P: Global cancer statistics, 2002. CA Cancer J Clin 55: 74-108, 2005.

3. El-Serag HB and Kanwal F: Epidemiology of hepatocellular carcinoma in the United States: Where are we? Where do we go? Hepatology 60: 1767-1775, 2014.

4. Bruix J and Sherman M; American Association for the Study of Liver Diseases: Management of hepatocellular carcinoma: An update. Hepatology 53: 1020-1022, 2011.

5. Hanahan D and Weinberg RA: Hallmarks of cancer: The next generation. Cell 144: 646-674, 2011.

6. Josic D, Clifton JG, Kovac S and Hixson DC: Membrane proteins as diagnostic biomarkers and targets for new therapies. Curr Opin Mol Ther 10: 116-123, 2008.

7. Boonstra MC, de Geus SW, Prevoo HA, Hawinkels LJ, van de Velde CJ, Kuppen PJ, Vahrmeijer AL and Sier CF: Selecting targets for tumor imaging: An overview of cancerassociated membrane proteins. Biomark Cancer 8: 119-133, 2016.

8. Mamede AC, Laranjo M, Carvalho MJ, Abrantes AM, Pires AS, Brito AF, Moura P, Maia CJ and Botelho MF: Effect of amniotic membrane proteins in human cancer cell lines: An exploratory study. J Membr Biol 247: 357-360, 2014.

9. Rucevic M, Hixson D and Josic D: Mammalian plasma membrane proteins as potential biomarkers and drug targets. Electrophoresis 32: 1549-1564, 2011.

10. Li SY, Yu B, An P, Liang ZJ, Yuan SJ and Cai HY: Effects of cell membrane phospholipid level and protein kinase $\mathrm{C}$ isoenzyme expression on hepatic metastasis of colorectal carcinoma. Hepatobiliary Pancreat Dis Int 3: 411-416, 2004.

11. Sun GG, Wang YD, Cui DW, Cheng YJ and Hu WN: Epithelial membrane protein 1 negatively regulates cell growth and metastasis in colorectal carcinoma. World J Gastroenterol 20: 4001-4010, 2014

12. Agarwal AK, Srinivasan N, Godbole R, More SK, Budnar S, Gude RP and Kalraiya RD: Role of tumor cell surface lysosomeassociated membrane protein-1 (LAMP1) and its associated carbohydrates in lung metastasis. J Cancer Res Clin Oncol 141: 1563-1574, 2015.

13. Lee TY, Chang HH, Kuo JJ and Shen JJ: Changes of hepatic proteome in bile duct ligated rats with hepatic fibrosis following treatment with Yin-Chen-Hao-Tang. Int J Mol Med 23: 477-484, 2009.

14. Ross PL, Huang YN, Marchese JN, Williamson B, Parker K, Hattan S, Khainovski N, Pillai S, Dey S, Daniels S, et al: Multiplexed protein quantitation in Saccharomyces cerevisiae using amine-reactive isobaric tagging reagents. Mol Cell Proteomics 3: 1154-1169, 2004.

15. Li Y, Tang ZY, Ye SL, Liu YK, Chen J, Xue Q, Chen J, Gao DM and Bao WH: Establishment of cell clones with different metastatic potential from the metastatic hepatocellular carcinoma cell line MHCC97. World J Gastroenterol 7: 630-636, 2001.

16. Wang C, Zhu ZM, Liu CL, He XJ, Zhang HY and Dong JH: Knockdown of yes-associated protein inhibits proliferation and downregulates large tumor suppressor 1 expression in MHCC $97 \mathrm{H}$ human hepatocellular carcinoma cells. Mol Med Rep 11: 4101-4108, 2015.

17. Zou YH, Li XD, Zhang QH and Liu DZ: RACK1 silencing induces cell apoptosis and inhibits cell proliferation in hepatocellular carcinoma MHCC97-H cells. Pathol Oncol Res 24: 101-107, 2018. 
18. Tian M, Cheng H, Wang Z, Su N, Liu Z, Sun C, Zhen B, Hong X, Xue Y and $\mathrm{Xu} P$ : Phosphoproteomic analysis of the highlymetastatic hepatocellular carcinoma cell line, MHCC97-H. Int J Mol Sci 16: 4209-4225, 2015.

19. Sun H and Liu GT: Inhibitory effect of anti-hepatitis drug bicyclol on invasion of human hepatocellular carcinoma MHCC97-H cells with high metastasis potential and its relative mechanisms. J Asian Nat Prod Res 11: 576-583, 2009.

20. Yang Y, Toy W, Choong LY, Hou P, Ashktorab H, Smoot DT, Yeoh KG and Lim YP: Discovery of SLC3A2 cell membrane protein as a potential gastric cancer biomarker: Implications in molecular imaging. J Proteome Res 11: 5736-5747, 2012.

21. Wang LN, Tong SW, Hu HD, Ye F, Li SL, Ren H, Zhang DZ, Xiang R and Yang YX: Quantitative proteome analysis of ovarian cancer tissues using a iTRAQ approach. J Cell Biochem 113: 3762-3772, 2012.

22. She S, Xiang Y, Yang M, Ding X, Liu X, Ma L, Liu Q, Liu B, Lu Z, $\mathrm{Li} \mathrm{S}$, et al: C-reactive protein is a biomarker of AFP-negative HBV-related hepatocellular carcinoma. Int J Oncol 47: 543-554, 2015.

23. Livak KJ and Schmittgen TD: Analysis of relative gene expression data using real-time quantitative PCR and the $2(-\Delta \Delta C(T))$ method. Methods 25: 402-408, 2001.

24. Bledi Y,Inberg A and Linial M: PROCEED: A proteomic method for analysing plasma membrane proteins in living mammalian cells. Brief Funct Genomics Proteomics 2: 254-265, 2003.

25. Josic D and Clifton JG: Mammalian plasma membrane proteomics. Proteomics 7: 3010-3029, 2007.

26. Zhang H, Tian B, Yu H, Yao H and Gao Z: LAPTM4B-35 protein as a potential therapeutic target in gastric cancer. Tumour Biol 35 12737-12742, 2014.

27. Yoshizaki T, Kondo S, Endo K, Nakanishi Y, Aga M, Kobayashi E, Hirai N, Sugimoto H, Hatano M, Ueno T, et al: Modulation of the tumor microenvironment by Epstein-Barr virus latent membrane protein 1 in nasopharyngeal carcinoma. Cancer Sci 109: 272-278, 2018.

28. Xue Q, Zhou Y, Wan C, Lv L, Chen B, Cao X, Ju G, Huang Y, Ni R and Mao G: Epithelial membrane protein 3 is frequently shown as promoter methylation and functions as a tumor suppressor gene in non-small cell lung cancer. Exp Mol Pathol 95: 313-318, 2013.

29. Liang S, Xu Z, Xu X, Zhao X, Huang C and Wei Y: Quantitative proteomics for cancer biomarker discovery. Comb Chem High Throughput Screen 15: 221-231, 2012.

30. Tian J, Tang Z and Ye S: Establishment of a human hepatocellular carcinoma $(\mathrm{HCC})$ cell line with high metastatic potentia (MHCC97) and its biological characteristics. Zhonghua Zhong Liu Za Zhi 20: 405-407, 1998 (In Chinese).

31. Tian J, Tang ZY, Ye SL, Liu YK, Lin ZY, Chen J and Xue Q: New human hepatocellular carcinoma (HCC) cell line with highly metastatic potential (MHCC97) and its expressions of the factors associated with metastasis. Br J Cancer 81: 814-821, 1999.

32. Chen B, Wang J, Dai D, Zhou Q, Guo X, Tian Z, Huang X, Yang L, Tang $\mathrm{H}$ and Xie X: AHNAK suppresses tumour proliferation and invasion by targeting multiple pathways in triple-negative breast cancer. J Exp Clin Cancer Res 36: 65, 2017.

33. Hoe SL, Tan LP, Abdul Aziz N, Liew K, Teow SY, Abdul Razak FR, Chin YM, Mohamed Shahrehan NA, Chu TL, Mohd Kornain NK, et al: CD24, CD44 and EpCAM enrich for tumour-initiating cells in a newly established patient-derived xenograft of nasopharyngeal carcinoma. Sci Rep 7: 12372, 2017.

34. Qin Q, Wei F, Zhang J and Li B: miR-134 suppresses the migration and invasion of non small cell lung cancer by targeting ITGB1. Oncol Rep 37: 823-830, 2017

35. Yáñez-Mó M, Barreiro O, Gordon-Alonso M, Sala-Valdés M and Sánchez-Madrid F: Tetraspanin-enriched microdomains: A functional unit in cell plasma membranes. Trends Cell Biol 19: 434-446, 2009

36. Zöller M: Tetraspanins: Push and pull in suppressing and promoting metastasis. Nat Rev Cancer 9: 40-55, 2009.

37. Hemler ME: Tetraspanin proteins mediate cellular penetration, invasion, and fusion events and define a novel type of membrane microdomain. Annu Rev Cell Dev Biol 19: 397-422, 2003.

38. Zijlstra A, Lewis J, Degryse B, Stuhlmann H and Quigley JP: The inhibition of tumor cell intravasation and subsequent metastasis via regulation of in vivo tumor cell motility by the tetraspanin CD151. Cancer Cell 13: 221-234, 2008.
39. Schröder HM, Hoffmann SC, Hecker M, Korff T and Ludwig T: The tetraspanin network modulates MT1-MMP cell surface trafficking. Int J Biochem Cell Biol 45: 1133-1144, 2013.

40. Boucheix C and Rubinstein E: Tetraspanins. Cell Mol Life Sci 58: 1189-1205, 2001

41. Boucheix C, Benoit P, Frachet P, Billard M, Worthington RE, Gagnon J and Uzan G: Molecular cloning of the CD9 antigen. A new family of cell surface proteins. J Biol Chem 266: 117-122, 1991.

42. Lanza F, Wolf D, Fox CF, Kieffer N, Seyer JM, Fried VA, Coughlin SR, Phillips DR and Jennings LK: cDNA cloning and expression of platelet p24/CD9. Evidence for a new family of multiple membrane-spanning proteins. J Biol Chem 266: 10638-10645, 1991.

43. Maecker HT, Todd SC and Levy S: The tetraspanin superfamily: Molecular facilitators. FASEB J 11: 428-442, 1997.

44. Miyake M, Nakano K, Itoi SI, Koh T and Taki T: Motility-related protein-1 (MRP-1/CD9) reduction as a factor of poor prognosis in breast cancer. Cancer Res 56: 1244-1249, 1996.

45. Copeland BT, Bowman MJ, Boucheix C and Ashman LK: Knockout of the tetraspanin Cd9 in the TRAMP model of de novo prostate cancer increases spontaneous metastases in an organ-specific manner. Int J Cancer 133: 1803-1812, 2013.

46. Hashida H, Takabayashi A, Tokuhara T, Taki T, Kondo K, Kohno N, Yamaoka Y and Miyake M: Integrin $\alpha 3$ expression as a prognostic factor in colon cancer: Association with MRP-1/CD9 and KAI1/CD82. Int J Cancer 97: 518-525, 2002.

47. Higashiyama M, Taki T, Ieki Y, Adachi M, Huang CL, Koh T, Kodama K, Doi O and Miyake M: Reduced motility related protein-1 (MRP-1/CD9) gene expression as a factor of poor prognosis in non-small cell lung cancer. Cancer Res 55: 6040-6044, 1995.

48. Fabian J, Opitz D, Althoff K, Lodrini M, Hero B, Volland R, Beckers A, de Preter K, Decock A, Patil N, et al: MYCN and HDAC5 transcriptionally repress CD9 to trigger invasion and metastasis in neuroblastoma. Oncotarget 7: 66344-66359, 2016.

49. Houle CD, Ding XY, Foley JF, Afshari CA, Barrett JC and Davis BJ: Loss of expression and altered localization of KAI1 and CD9 protein are associated with epithelial ovarian cancer progression. Gynecol Oncol 86: 69-78, 2002.

50. Sauer G, Windisch J, Kurzeder C, Heilmann V, Kreienberg R and Deissler H: Progression of cervical carcinomas is associated with down-regulation of CD9 but strong local re-expression at sites of transendothelial invasion. Clin Cancer Res 9: 6426-6431, 2003.

51. Wang JC, Bégin LR, Bérubé NG, Chevalier S, Aprikian AG, Gourdeau $\mathrm{H}$ and Chevrette M: Down-regulation of $\mathrm{CD} 9$ expression during prostate carcinoma progression is associated with CD9 mRNA modifications. Clin Cancer Res 13: 2354-2361, 2007.

52. Herr MJ, Kotha J, Hagedorn N, Smith B and Jennings LK: Tetraspanin CD9 promotes the invasive phenotype of human fibrosarcoma cells via upregulation of matrix metalloproteinase-9. PLoS One 8: e67766, 2013.

53. Zheng R, Yano S, Zhang H, Nakataki E, Tachibana I, Kawase I, Hayashi S and Sone S: CD9 overexpression suppressed the liver metastasis and malignant ascites via inhibition of proliferation and motility of small-cell lung cancer cells in NK cell-depleted SCID mice. Oncol Res 15: 365-372, 2005.

54. Uhlén M, Fagerberg L, Hallström BM, Lindskog C, Oksvold P, Mardinoglu A, Sivertsson A., Kampf C, Sjöstedt E, Asplund A, et al: Proteomics. Tissue-based map of the human proteome. Science 347: 1260419, 2015.

55. Sho M,Adachi M,Taki T,Hashida H,Konishi T,Huang CL, Ikeda N, Nakajima Y, Kanehiro H, Hisanaga M, et al: Transmembrane 4 superfamily as a prognostic factor in pancreatic cancer. Int $\mathrm{J}$ Cancer 79: 509-516, 1998.

56. Mori M, Mimori K, Shiraishi T, Haraguchi M, Ueo H, Barnard GF and Akiyoshi T: Motility related protein 1 (MRP1/CD9) expression in colon cancer. Clin Cancer Res 4: 1507-1510, 1998. 